\title{
Effect of Resin Coating on Surface Roughness and Microhardness of High Viscous Glass lonomer Cements
}

ARTICLE INFO

Submitted: $11 / 5 / 2021$

Accepted: 30/8/2021

Online: 22/12/2021

\author{
Jian Sheng Lee ${ }^{a}$, Wen Ni Chan ${ }^{a}$, Noor Azlin Yahya ${ }^{b}$, Ros Anita Omar ${ }^{b^{*}}$ \\ ${ }^{a}$ Faculty of Dentistry, Universiti Malaya, 50603 Kuala Lumpur, \\ Malaysia \\ ${ }^{b}$ Department of Restorative Dentistry, Faculty of Dentistry, \\ Universiti Malaya, 50603 Kuala Lumpur, Malaysia \\ *Corresponding author: anitaomar@um.edu.my
}

To cite this article: Lee JS, Chan WN, Yahya NA, Omar RA (2021). Effect of resin coating on surface roughness and microhardness of high viscous glass ionomer cements. Arch Orofac Sci, 16(2): $209-221$. https://doi.org/10.21315/aos2021.16.2.11

To link to this article: https://doi.org/10.21315/aos2021.16.2.11

\begin{abstract}
High viscous glass ionomer cement (HVGIC) was recently developed for atraumatic restorative treatment (ART). However, its moisture sensitivity remains a limitation thus protective coating application is recommended. This study investigated the effect of resin coating on the surface roughness and microhardness of two HVGICs (Riva Self Cure HVGIC [RV] and Equia ${ }^{\circledR}$ Forte Fil [EQ]) conditioned in food-simulating liquids (FSLs). Fifty standard disc-shaped samples were fabricated using customised stainless-steel mould $(10 \times 2 \mathrm{~mm})$. Coating was applied on top surface of all samples and subsequently divided into five groups: air (control), distilled water, $0.02 \mathrm{~N}$ citric acid, heptane and $50 \%$ ethanol-water solution. The samples were conditioned in FSLs at $37^{\circ} \mathrm{C}$ for seven days. Subsequently, the surface roughness and microhardness of samples were measured using optical profilometry and microhardness tester, respectively. SEM analysis was done for qualitative observation of surface morphological changes. Data were analysed using one-way ANOVA, two-way ANOVA and posthoc Tukey's test $(\alpha=0.05)$. Interestingly, the results revealed that surface roughness was significantly influenced by FSLs immersion, presence of coating and the materials itself $(p<0.001)$. The lowest

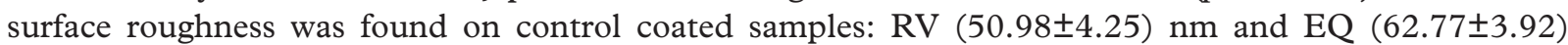
$\mathrm{nm}$, while the highest values seen on uncoated surfaces in citric acid: RV (505.26 \pm 31.10$) \mathrm{nm}$ and EQ (350.33 \pm 15.36$) \mathrm{nm}$. RV samples had the lowest microhardness of $54.97 \pm 2.48$ Vickers hardness number (VHN) post-immersion in citric acid. In conclusion, with the exception of RV conditioned in heptane and ethanol, the uncoated HVGICs generally had higher surface roughness than the coated HVGICs. HVGICs conditioned in citric acid showed the most significant increase in surface roughness and reduction in microhardness.
\end{abstract}

Keywords: Food-simulating liquids; high viscous glass ionomer cements; microhardness; surface roughness

\section{INTRODUCTION}

Glass ionomer cement (GIC) was first developed in the 1970s (Wilson \& Kent, 1971). Its wide usage in dentistry as luting agent (type I), restorative material (type II) and lining (type III) is attributed by its aesthetic appearance, biocompatibility to oral cavity, chemical bonding to tooth structure and fluoride-releasing properties (Sidhu \& Nicholson, 2016). 
Over the years, the alteration of GIC's material formulation sought to enhance the cement in aspects such as fluoridereleasing, moisture sensitivity, mechanical and antibacterial properties. For example, fibre-reinforcement, resin-modification and metal powders additives were incorporated to reinforce the material (Lyapina et al., 2016) while coumarin derivatives were added to synergize with the fluoride-releasing property to elevate the anti-cariogenic activity of GIC (Azlisham et al., 2017). Besides additives, filler properties such as size, morphology, distribution, amount of particles and bonding interface between particles had been proven to influence surface profile of GIC (Gladys et al., 1997) while other studies demonstrated that the incorporation of nanoparticles to GIC gave higher mechanical values as a result of wider particle size distribution (Moshaverinia et al., 2008).

Surface roughness of a restorative material is crucial as it proved that surfaces which exceed the threshold value of $\mathrm{Ra}=200$ $\mathrm{nm}$, contributes to increase bacterial accumulation and caries (Bollen et al., 1997). Moreover, mechanical strength of a restorative material determines its resistance to masticatory stress in the oral cavity that is on average, range between $5 \mathrm{MPa}$ to $20 \mathrm{MPa}$ at a frequency of $2 \mathrm{~Hz}$ (Braem et al., 1994).

High viscous GIC (HVGIC) has gained popularity in contemporary dentistry recently, especially in paediatric dentistry, where this material is considered a viable option to restore dental caries lesions (Berg \& Croll, 2015). HVGIC has a different powder-liquid ratio, particle size and distribution compared to conventional GIC which strengthen the mechanical properties of the material (Friedl et al., 2011). Due to its bulk application, this material is easy to handle with acceptable physical-mechanical properties. In addition, this material presents good biocompatibility and chemical adhesion to tooth structures, as well as the ability to release fluoride (Yildiz et al., 2016; Hesse et al., 2018), hence, minimising caries by forming fluorapatite crystals, which are more acid resistant (Perrin et al., 1994).

In early 1990's, HVGIC was developed for use in atraumatic restorative treatment (ART) (Yilmaz et al., 2006), a treatment done without electricity or conventional dental chair (Frencken et al., 2004). However, HVGIC has some limitations such as sensitive to moisture, low mechanical strength, rough surface and porous (Yildiz et al., 2016). For instance, during setting, similar as GIC, HVGIC has to be protected from moisture contamination that may lead to surface wear and reduced translucency due to dissolution of metal cations. In addition, the maturation of GIC and HVGIC that occur 24 hours after it has set also needs to be protected from dehydration to avoid microcracks which significantly compromise the mechanical strength of the restoration (Hesse et al., 2018), subsequently rendering the surface more prone to erosion and abrasion (Gemalmaz et al., 1998).

A previous study revealed that nanofilled protective coating (NPC) had more protective effect on the clinical wear of approximal GIC restorations in primary teeth compared to petroleum jelly (Hesse et al., 2018). Similarly, recently introduced bulk-fill reinforced GIC, Riva Self Cure HVGIC (RV) and Equia ${ }^{\circledR}$ Forte Fil (EQ) were recommended to be used together with respective NPCs (Riva Coat and Equia ${ }^{\circledR}$ Forte Coat) by manufacturers. EQ showed that with the application of a multifunctional monomer layer, "microlaminate" restorations with improved physical and aesthetic properties are achieved. A prospective six-year clinical trial using the "microlamination" technique proved the reliability of this restorative approach (Türkün \& Kanik, 2016). However, information regarding the influence of foodsimulating liquids (FSLs) on the surface roughness and microhardness of coated and uncoated HVGICs is still lacking in the literature. 
Therefore, the objectives of this study were to compare the surface roughness and microhardness of $\mathrm{RV}$ and $\mathrm{EQ}$ after conditioning in different FSLs. The effect of resin coating on the properties of these HVGICs were also evaluated. The null hypotheses were that there were no differences in surface roughness and microhardness of both HVGICs, with and without coating as well as after conditioning in FSLs.

\section{MATERIALS AND METHODS}

\section{Materials}

The materials evaluated in this study were SDI RV and GC America EQ. Details of the materials and their technical profiles are shown in Table 1.

\section{Samples Preparation}

A total of $50(n=50)$ samples each were made for both RV and EQ. The disc-shaped samples were prepared using a customised stainless steel mold $(10 \mathrm{~mm} \times 2 \mathrm{~mm})$. The top and bottom surfaces of the mold were covered with cellulose acetate matrix strip to ensure smooth surfaces of the samples.
Excess material was removed by compressing the molds between two matrix strips with glass slides before light cured for $20 \mathrm{sec}$. Riva Coat and Equia ${ }^{\circledR}$ Forte Coat were applied over the top surfaces of all RV and EQ samples respectively and light cured for $20 \mathrm{sec}$ with light curing unit (Bluephase $\mathrm{N}$, lycolar Vivadent, Schaan, Liechtenstein, high power, wavelength of $1,200 \mathrm{~mW} / \mathrm{cm}^{2}$ ) according to manufacturers' instructions, while the bottom surfaces were left uncoated. The coated surfaces were marked to differentiate it from the uncoated surfaces. All samples were subsequently measured with a digital caliper (Mitutoyo Corporation, Kawasaki, Japan) to ensure size consistency. The samples were then incubated in an incubator (Memmert Incubator 1N750, Germany) for $24 \mathrm{~h}$ at a temperature of $37^{\circ} \mathrm{C}$, with $100 \%$ humidity for post cure. The samples were randomly divided into five groups $(n=10)$; distilled water, $0.02 \mathrm{~N}$ citric acid, heptane, $50 \%$ ethanol-water solution and air (control) (see Table 2). All samples were conditioned in respective FSLs at $37^{\circ} \mathrm{C}$ for seven days. After conditioning, samples were gently dabbed dry with absorbent paper before subjected to surface profilometry and microhardness test.

Table 1 Brief technical profile and manufacturers of the materials used in the study

\begin{tabular}{|c|c|c|c|c|}
\hline $\begin{array}{l}\text { Material } \\
\text { (Abbreviation) }\end{array}$ & Manufacturer & $\begin{array}{l}\text { Type and } \\
\text { Method of } \\
\text { Curing }\end{array}$ & Resin/ Liquid & Filler/ Powder \\
\hline $\begin{array}{l}\text { Riva Self Cure } \\
\text { HVGIC (RV) }\end{array}$ & $\begin{array}{l}\text { SDI } \\
\text { Bayswater, } \\
\text { Australia }\end{array}$ & $\begin{array}{l}\text { HVGIC } \\
\text { (self-cured) }\end{array}$ & $\begin{array}{l}\text { Acrylic acid homopolymer, } \\
\text { 2-hydroxyethyl methacrylate, } \\
\text { dimethacrylate cross-linker, } \\
\text { acid monomer, tartaric acid }\end{array}$ & $\begin{array}{l}\text { Strontium } \\
\text { fluoroaluminosilicate } \\
\text { glass, polyacrylic acid } \\
\text { copolymer powders, } \\
\text { pigments }\end{array}$ \\
\hline $\begin{array}{l}\text { Riva Coat } \\
\text { (RV Coat) }\end{array}$ & & $\begin{array}{l}\text { NPC } \\
\text { (Light cured) }\end{array}$ & Multifunctional monomers & Nano-filler \\
\hline Equia $^{\circledR}$ Forte Fil (EQ) & $\begin{array}{l}\text { GC Industrial } \\
\text { Co., Tokyo, } \\
\text { Japan }\end{array}$ & $\begin{array}{l}\text { HVGIC } \\
\text { (Self-cured) }\end{array}$ & Aqueous polyacrylic acid & $\begin{array}{l}\text { Strontium } \\
\text { fluoroaluminosilicate } \\
\text { glass, polyacrylic acid }\end{array}$ \\
\hline $\begin{array}{l}\text { Equia }^{\circledR} \text { Forte Coat } \\
\text { (EQ Coat) }\end{array}$ & & $\begin{array}{l}\text { NPC } \\
\text { (Light cured) }\end{array}$ & $\begin{array}{l}\text { Methyl methacrylate, colloidal } \\
\text { silica, camphoroquinone, } \\
\text { urethane methacrylate, } \\
\text { phosphoric ester monomer }\end{array}$ & Nano-filler \\
\hline
\end{tabular}


Table 2 Samples grouping based on immersion in different FSLs

\begin{tabular}{cl} 
Groups & $\begin{array}{l}\text { Medium/condition of food simulating } \\
\text { liquids }\end{array}$ \\
\hline 1 & Air (control) \\
2 & Distilled water \\
3 & 0.02 N Citric acid \\
4 & Heptane \\
5 & $50 \%$ Ethanol-water solution \\
\hline
\end{tabular}

\section{Surface Roughness Analysis}

Surface roughness of each sample was measured using the 3D Optical Surface Texture Analyzer (ALICONA, InfiniteFocus Real3D, Belgium). The magnification was fixed at $20 \times$ while the vertical and lateral resolutions were automatically set at $308 \mathrm{~nm}$ and $2.93 \mu \mathrm{m}$, respectively. The average roughness value, $\mathrm{Ra}$ (average peaks and valleys on a surface) as a numeric value (in nanometers), was taken as the mean of $\mathrm{Ra}$ measured in five different locations on each sample. The measurements calculated and tabulated as mean and standard deviation.

\section{Microhardness Measurements}

The microhardness of each sample was tested post-conditioning using a fully automated microhardness tester (Shimadzu Corp, Kyoto, Japan) to attain the Vickers hardness number (VHN). Three indentations were made on each sample (both sides) using a pyramidal shaped diamond penetrator with a square base and an angle of $136^{\circ}$, with a fix load of $50 \mathrm{~g}$ for $15 \mathrm{sec}$ dwell time. The measurements were then translated to the microhardness value as VHN. The mean values and standard deviations of VHN from three different locations of each sample were calculated and tabulated.

\section{Scanning Electron Microscopy Analysis}

Samples from each group was randomly selected and prepared for qualitative observation of the surface morphological changes using scanning electron microscope (SEM) (Quanta-FEG 50, FEI, Germany). Samples were mounted on metallic stubs, dried at $37^{\circ} \mathrm{C}$, sputter-coated with gold and viewed under vacuum at an acceleration voltage of $10 \mathrm{kV}$. micrographs images were obtained at $3000 \times$ magnification.

\section{Statistical Analysis}

Statistical analysis was performed using Statistical Package for the Social Sciences (SPSS) software (version 12.0.1, SPSS Inc, Chicago, IL, US). Data were checked for normality using the Kolmogorov-Smirnov and Shapiro-Wilk test and were found to be normally distributed. Therefore, parametric analysis with post-hoc Tukey's test was used to determine significant differences among materials at a significance level $p<0.05$. Interactions between independent variables (namely test materials, presence of coating and FSLs) were evaluated using two-way ANOVA while one-way ANOVA were conducted to establish the inter-medium differences in the microhardness test. Both ANOVA were conducted at $95 \%$ confidence interval.

\section{RESULTS}

\section{Surface Roughness}

Tables 3 and 4 show the means and standard deviations of surface roughness of coated and uncoated $R V$ and $E Q$, respectively. In general, two-way ANOVA revealed a statistically significant influence of "FSLs immersion" $(p<0.001)$, "presence of coating" ( $p<0.001)$ and "test materials" $(p<0.001)$ on surface roughness for both materials tested. The interaction between "FSLs immersion" and "presence of coating" on surface roughness of samples was significant $(p<0.001)$. Likewise, there was a significant interaction between "FSLs immersion" and "test materials" $(p<0.001)$ on surface roughness of samples. 
Table 3 Means and standard deviations of surface roughness (Ra) of coated and uncoated RV in different FSLs

\begin{tabular}{lcc} 
Solutions & \multicolumn{2}{c}{ RV } \\
\cline { 2 - 3 } & Coated $(\mathbf{n m})$ & Uncoated $(\mathbf{n m})$ \\
\hline Air (control) & $50.98 \pm 4.25^{\mathrm{a}, 1}$ & $196.42 \pm 17.51^{\mathrm{a}, 2}$ \\
Distilled water & $71.34 \pm 6.37^{\mathrm{a}, 1}$ & $206.39 \pm 18.78^{\mathrm{a}, 2}$ \\
0.02 N Citric acid & $420.13 \pm 25.44^{\mathrm{b}, 1}$ & $505.26 \pm 31.10^{\mathrm{b}, 2}$ \\
Heptane & $275.52 \pm 26.27^{\mathrm{c}, 1}$ & $194.54 \pm 16.42^{\mathrm{a}, 2}$ \\
50\% Ethanol-water solution & $241.94 \pm 23.78^{\mathrm{d}, 1}$ & $193.45 \pm 18.62^{\mathrm{a}, 2}$ \\
\hline
\end{tabular}

Notes: Different superscript letters indicate statistical difference between rows (FSLs immersion). Different superscript numbers indicate statistical difference between columns (presence of coating).

Table 4 Means and standard deviations of surface roughness (Ra) of coated and uncoated EQ in different FSLs

\begin{tabular}{lcc} 
Solutions & \multicolumn{2}{c}{ EQ } \\
\cline { 2 - 3 } & Coated $(\mathbf{n m})$ & Uncoated $(\mathbf{n m})$ \\
\hline Air (control) & $62.77 \pm 3.92^{\mathrm{a}, 1}$ & $189.6 \pm 9.50^{\mathrm{a}, 2}$ \\
Distilled water & $134.4 \pm 11.28^{\mathrm{b}, 1}$ & $341.25 \pm 12.94^{\mathrm{b}, 2}$ \\
$0.02 \mathrm{~N}$ Citric acid & $156.98 \pm 9.19^{\mathrm{c}, 1}$ & $350.33 \pm 15.36^{\mathrm{b}, 2}$ \\
Heptane & $130.08 \pm 6.30^{\mathrm{b}, 1}$ & $291.72 \pm 9.71^{\mathrm{c}, 2}$ \\
$50 \%$ Ethanol-water solution & $139.4 \pm 8.21^{\mathrm{b}, 1}$ & $346.83 \pm 9.98^{\mathrm{b}, 2}$ \\
\hline
\end{tabular}

Notes: Different superscript letters indicate statistical difference between rows (FSLs immersion). Different superscript numbers indicate statistical difference between columns (presence of coating).

Post-hoc Tukey's test showed that statistically there was no difference in the surface roughness values of coated and uncoated RV samples after immersion in distilled water when compared to control $(p=0.119)$. Significantly higher roughness values were observed in RV coated samples after immersion in citric acid, heptane and ethanol $(p<0.001)$ while the highest roughness values were seen in citric acid for both coated and uncoated samples. Overall, uncoated RV samples were significantly rougher than the coated samples $(p<0.05)$ except for samples immersed in heptane and ethanol where coated samples were significantly rougher than the uncoated samples $(p<0.05)$ (see Table 3 and Fig. 1). For EQ, generally the surface roughness values of all samples significantly increased after immersion in FSLs as compared to control $(p<0.05)$ with uncoated samples significantly rougher than coated samples $(p<0.05)$ (see Table 4 and Fig. 1).

\section{Microhardness}

The means and standard deviations of microhardness in VHN of the samples are shown in Table 5. One-way ANOVA revealed that immersion of both $\mathrm{RV}$ and EQ uncoated samples in citric acid resulted in a significant reduction of microhardness as compared to control $(p<0.001)$. Besides, there was a significant increase in microhardness of uncoated EQ samples after immersion in heptane as compared to control $(p<0.05)$. Whereas, RV samples immersed in citric acid had the lowest microhardness value of $54.97 \pm 2.48 \mathrm{VHN}$. 
The results also revealed that the indentation from the applied load formed on the coated surface (see Fig. 2a) of a RV samples was a cross-shaped indentation instead of a typical diamond-shaped Vickers indentation as shown on the uncoated surface (see Fig. 2b). The indentation on the coated surface did not have well-defined points of measurement, thus a VHN cannot be determined. On the contrary, VHN can be calculated on the uncoated surface as the indentation was distinct and clear (see Fig. 2).

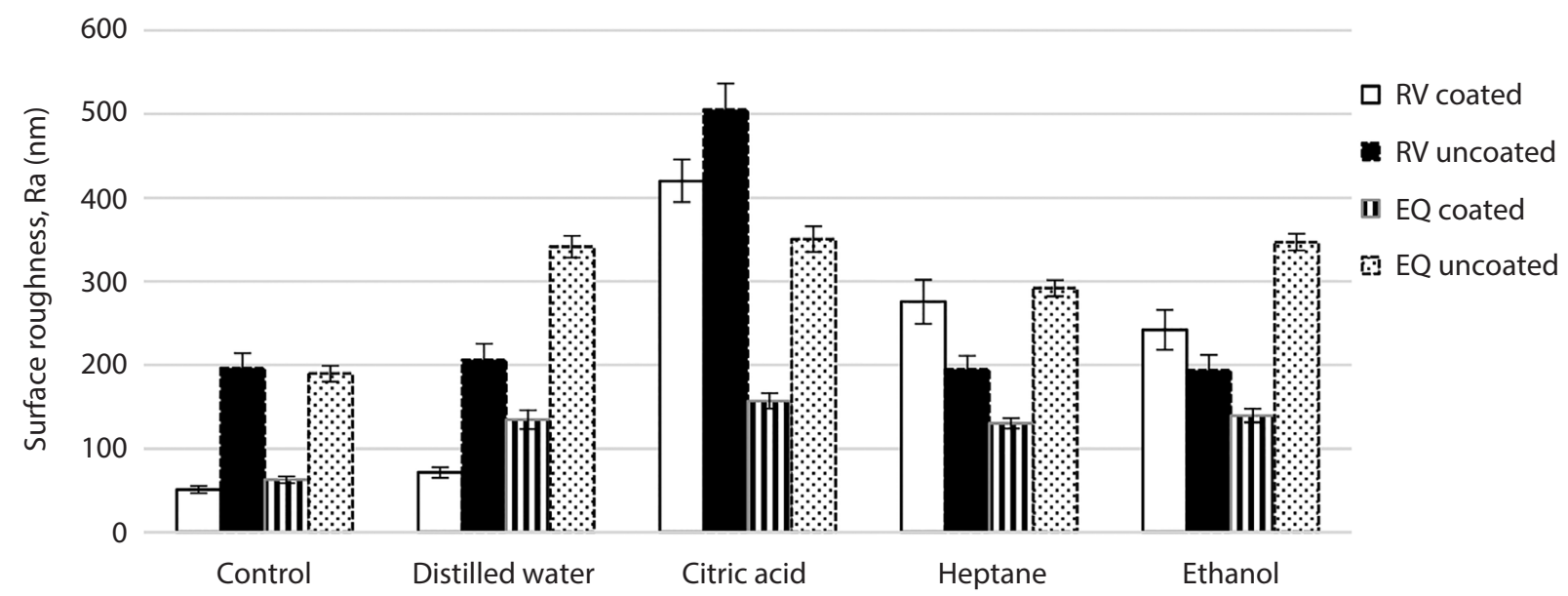

Fig. 1 Means and standard deviations of surface roughness values of all test materials in different FSLs.

Table 5 Mean VHN with standard deviations of uncoated test materials in different FSLs

\begin{tabular}{lcccc} 
Solutions & RV & $\boldsymbol{p}$ & EQ & $\boldsymbol{p}$ \\
Air (control) & $97.60 \pm 5.25$ & - & $105.10 \pm 9.19$ & - \\
Distilled water & $103.28 \pm 9.88$ & 0.306 & $110.01 \pm 9.31$ & 0.557 \\
0.02 N Citric acid & $54.97 \pm 2.48^{*}$ & 0.000 & $89.22 \pm 7.32^{*}$ & 0.000 \\
Heptane & $101.92 \pm 7.71$ & 0.578 & $115.96 \pm 3.00^{*}$ & 0.013 \\
50\% Ethanol-water solution & $95.28 \pm 4.62$ & 0.930 & $101.67 \pm 2.86$ & 0.826 \\
\hline
\end{tabular}

Note: *statistically significant difference $(p<0.05)$

(a) Coated surface

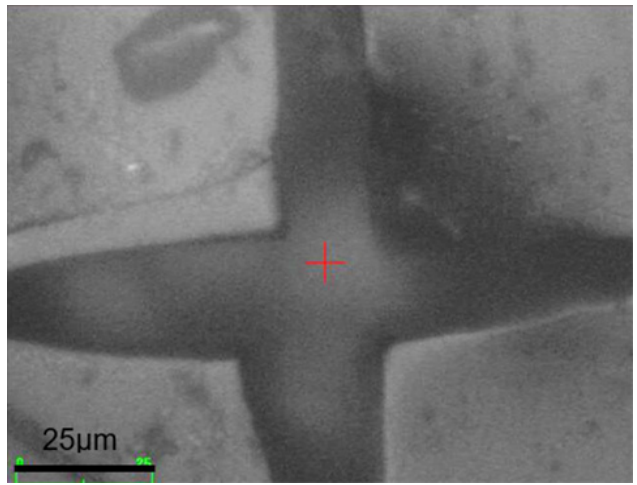

(a) Uncoated surface

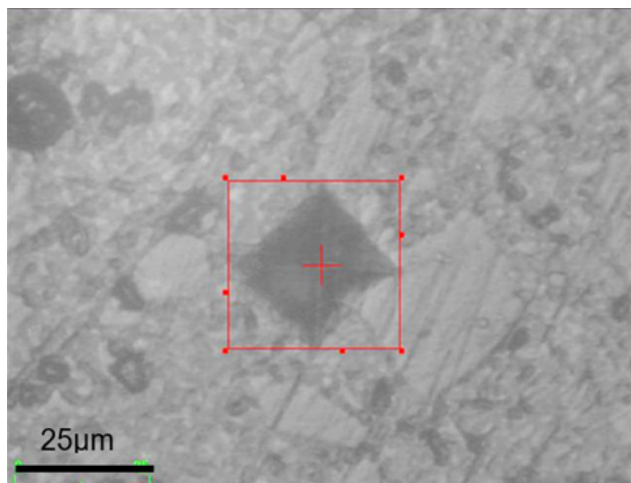

Fig. 2 Vickers hardness test images of RV samples, (a) coated and (b) uncoated surfaces at control. 


\section{SEM Analysis}

Figs. 3 and 4 showed that all uncoated samples presented with microcracks for control and post-immersion in FSLs as pointed by the black arrows. The amount of microcracks visible on uncoated surfaces of both RV and EQ immersed in citric acid was more than that of control. White arrows indicate visible filler content within both RV and EQ at control and post-immersion in all FSLs except for citric acid. Pits were absent on uncoated surfaces of both RV and EQ in the control and distilled water but were present in all other solutions as indicated by yellow arrows. On the contrary, no filler content, microcracks and pits formation were visible on all of the coated surfaces for both $\mathrm{RV}$ and EQ at control and post-immersion in FSLs.

\section{DISCUSSION}

In this study, the effect of resin coating on surface roughness and microhardness of both HVGICs (RV and EQ) conditioned in different FSLs were analysed. It was revealed that the surface roughness and microhardness were material and conditioning medium-dependent, hence the null hypothesis was rejected.

The FSLs used for conditioning HVGIC materials in this study were based on the guidelines from Food and Drug Administration (1976), for example, distilled water to simulate the wet environment of oral cavity provided by saliva and water; citric acid and ethanol to mimic acidic and certain beverages including alcohol, vegetables, fruits, candies and syrups; and heptane to simulate animal and vegetable fat such as butter, fatty meats and vegetable oils. The continuous seven days conditioning period of HVGIC materials at $37^{\circ} \mathrm{C}$ prior to testing though reported to provide the most remarkable differences in physical properties of restorative materials (Kao, 1989), may appear rather extensive as restorations contact with foods and liquids only briefly and sporadically during function. Therefore, the current test results may exaggerate the effects of food substances and liquids in vivo. However, continuous exposure may occur in vivo as chemicals are absorbed by adherent debris (such as calculus or food particles) at the margins or grooves of restorations (Yap \& Wee, 2002; Akova et al., 2006). Presence of saliva may reduce or balance the action of these chemicals; unfortunately, this buffering effect of saliva is not able to be simulated in this study.

Bollen et al. (1997) reported that the surface roughness threshold value for plaque retention was $\mathrm{Ra}=200 \mathrm{~nm}$. In the present study, the mean surface roughness values of both uncoated control $\mathrm{RV}$ and EQ surfaces were below the threshold value of $(196.42 \pm 17.51) \mathrm{nm}$ and $(189.61 \pm 9.50)$ $\mathrm{nm}$, respectively. This could be due to the use of cellulose acetate matrix strip during sample preparation that provides smoother surface finish of sample surfaces. This was proven when Bagheri et al. (2007) showed that GIC surface was smoother than polishing it when matrix strip was used. At post-immersion, surface roughness of all uncoated samples were significantly increased $(p<0.001)$. For distilled water and $50 \%$ ethanol-water solution, the increased surface roughness can be attributed from water sorption into resin matrix of HVGICs which has a dissolution and degradation effect (Sideridou \& Karabela, 2011). The erosion of HVGICs by $0.02 \mathrm{~N}$ citric acid was due to the diffusion of $\mathrm{H}^{+}$ions into the glass ionomer contents of which the quantity is directly proportional to the $\mathrm{pH}$ value of the solution. $\mathrm{H}^{+}$ions replaced metal cations and bind to polycarboxylic acid molecules while the latter were released to the surface, producing peaks and troughs, which in turn rendering the surface rougher (Fukazawa et al., 1987). This could explain why SEM images of both RV and EQ uncoated samples conditioned in citric acid (Figs. 3 and 4) presented with more microcracks and pits while filler contents were not visible within the HVGICs. 


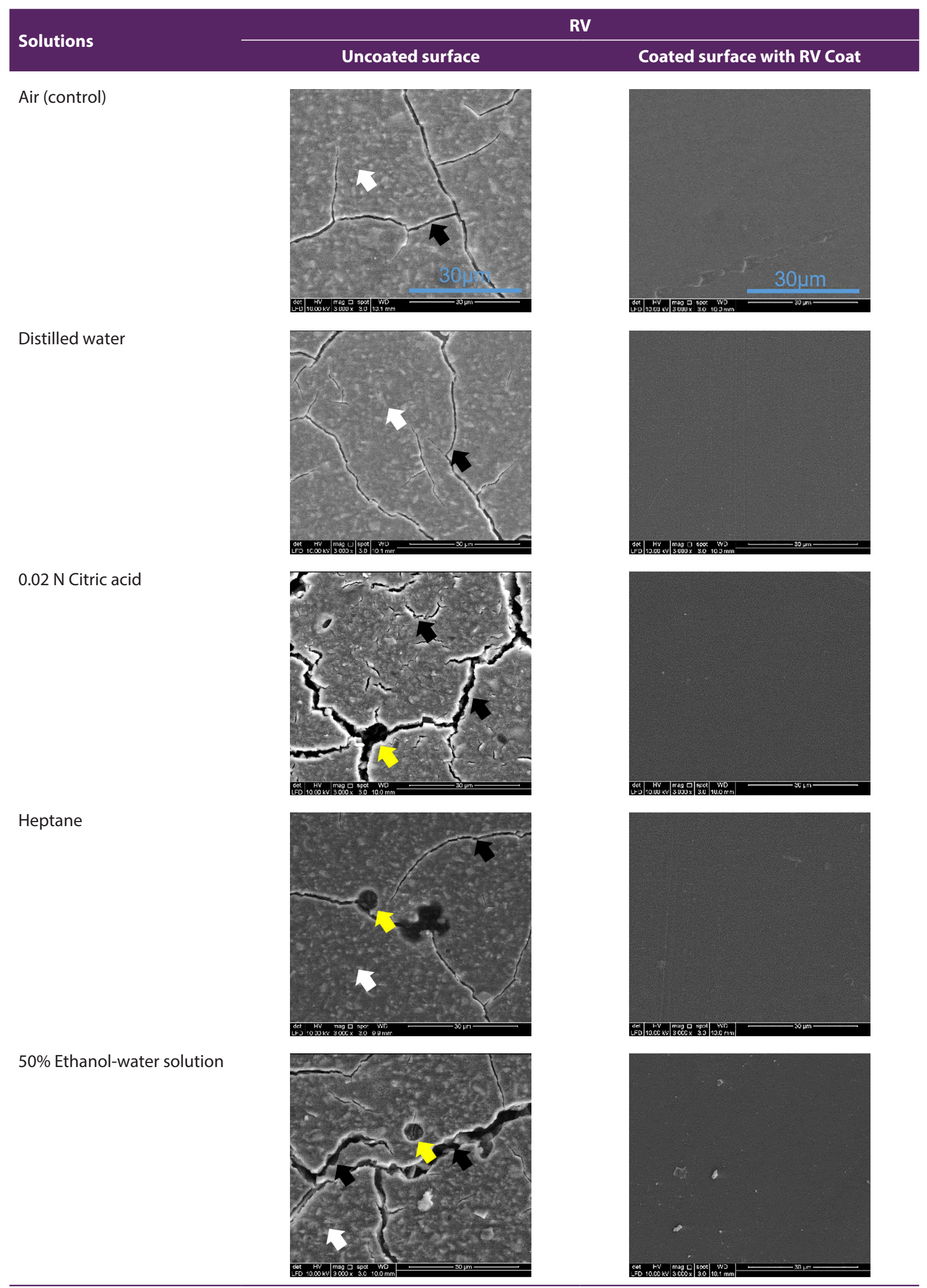

Fig. 3 SEM images of uncoated and coated surfaces of RV samples at 3,000 $\times$ magnification. 


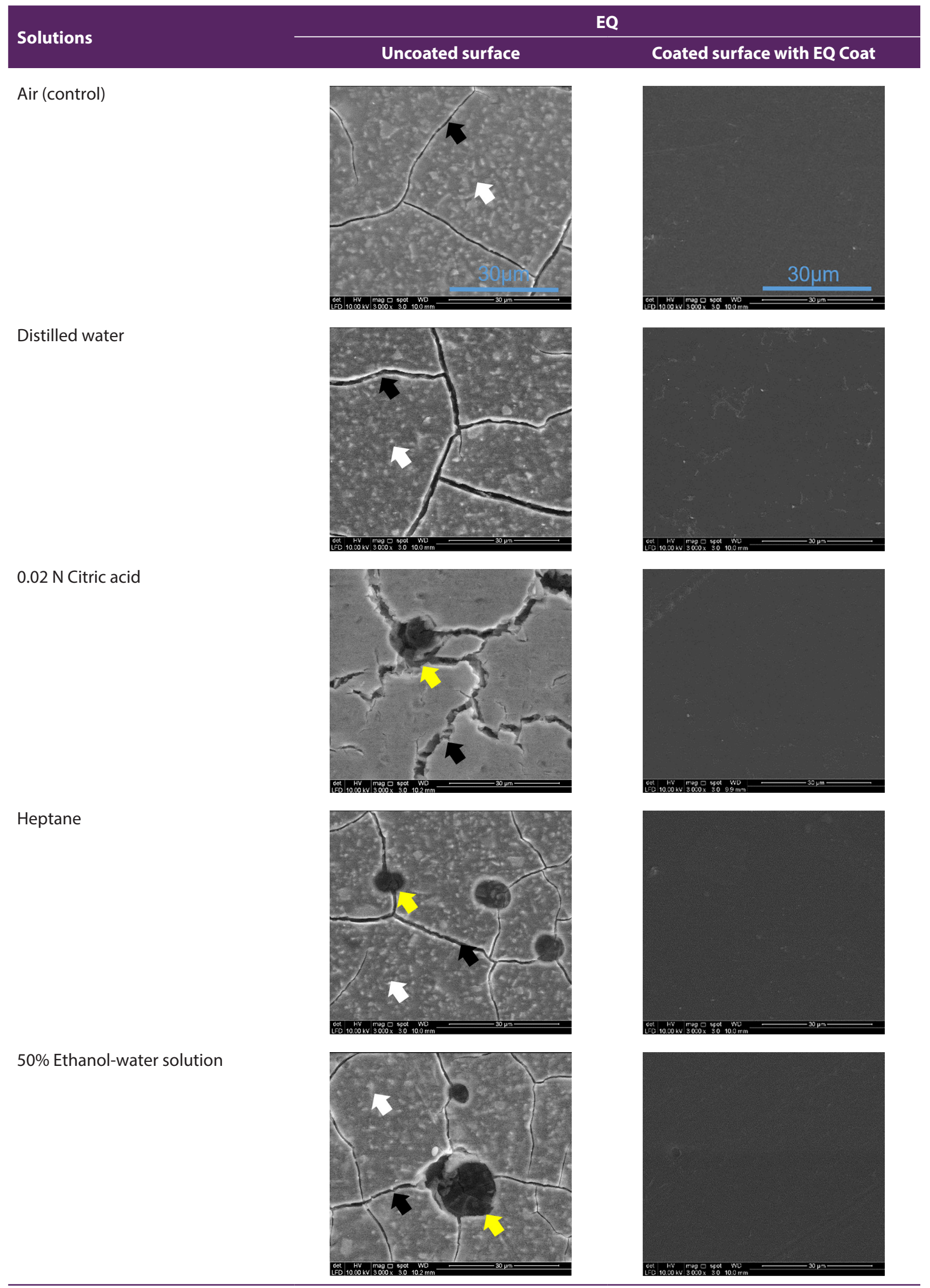

Fig. 4 SEM images of uncoated and coated surfaces of EQ samples at 3,000× magnification. 
With the exception of RV conditioned in heptane and ethanol, coated surfaces were relatively smoother than uncoated samples. SEM images of coated RV and EQ samples showed no microcracks and pits in all FSLs and control. This observation can be due to the sealing of surface porosities and cracks by NPC (Lohbauer et al., 2011). Various studies had been investigating the effect of surface protection on GIC by petroleum jelly and NPC against moisture contamination. The present study was in agreement with Hesse et al. (2016) where they reported the surface coated with NPC exhibited lower Ra values and the survival rate of conventional GIC in approximal ART restoration was increased by application of NPC. Diem et al. (2014) also reported that application of G-Coat Plus provided wear resistance on Fuji IX GP Extra. In contrast, Pacifici et al. (2013) reported that the presence of coating had no significant effect on surface roughness of resin modified GICs and HVGICs. Likewise, Lohbauer et al. (2011) also showed that the application of coating did not improve the wear resistance of GIC although it provided a proper sealing for surface porosities and cracks. This could explain why in the present study, the surface roughness of RV coated samples conditioned in heptane and ethanol was higher than that of the uncoated samples. Another reason could be due to the chemical interaction of RV coat with heptane and ethanol that led to improper sealing. However, to confirm this, further study is required.

In terms of microhardness, an ideal dental material should have good mechanical properties such as fracture toughness, flexural strength and microhardness (McLean, 1990). For instance, the restorative materials should be able to withstand masticatory stress that is averagely ranged between $5 \mathrm{MPa}$ to $20 \mathrm{MPa}$ at a frequency of $2 \mathrm{~Hz}$ (Braem et al., 1994). In this study, all uncoated samples were subjected to Vickers hardness test. Vickers method was chosen over Knoop because the former creates a square indentation, which is more suitable for small, rounded specimen while the latter creates an elongated indentation that is more suitable for small and long specimens (EMCOTEST Prüfmaschinen GmbH, 2019). In the present study however, the indentations on coated samples were indistinct and unmeasurable (Fig. 2). The reason could be due to lower microhardness of NPC relative to the HVGICs surfaces as reported by Faraji et al. (2017) that the conventional GIC without protective coating has higher VHN than coated GIC and the uneven thickness of the coating itself. In general, protective coatings do not have the required mechanical properties of a suitable restorative material.

In the present study, a significant decrease in microhardness of uncoated surfaces of both RV and EQ when immersed in citric acid could be due to the dissolution of the bonding between metal cations and polycarboxylic acid that compromises the mechanical strength of GIC (Fukazawa et al., 1987). Additionally, HEMA (2-hydroxyethyl methacrylate) was eluted from resin modified GIC after immersion in acidic medium for seven days (Rogalewicz et al., 2006). The incomplete polymerisation produces residual monomer which facilitates higher degree of dissolution within the GIC. However, a significant increase in microhardness of EQ was observed after immersion in heptane. This result was in agreement with Yap et al. (2003) who reported that the reduction of oxygen inhibition layer by heptane occurred during post-curing and also impeding silica and combined metals from leaching out of fillers.

In this study, the immersion of both HVGICs in FSLs significantly increased the surface roughness of HVGIC while application of protective coating significantly reduced the surface roughness of HVGIC with the exception of RV samples in heptane and ethanol. Immersion in citric acid significantly reduced the microhardness of both RV and EQ while the latter was significantly hardened after immersion in heptane. These observations were in accordance with previous studies 
(Diem et al., 2014; Hesse et al., 2016) in demonstrating the effectiveness of protective coating on the physical properties of HVGICs. Therefore, these highlighted the clinical importance of applying protective coating to improve longevity of HVGICs restorations.

\section{CONCLUSION}

Within the limitations of this in vitro study, the effect of FSLs on surface roughness and microhardness of HVGICs was found to be material and conditioning medium dependent. Generally, HVGICs exhibited highest surface roughness and lowest microhardness when exposed to citric acid. With the exception of RV conditioned in heptane and ethanol, the uncoated HVGICs generally had higher surface roughness than the coated HVGICs. Additionally, no apparent microcracks or pits formation were evidence on all coated surfaces, suggesting that the application of resin coating is of greater clinical relevance to increase longevity of HVGIC restorations.

\section{ACKNOWLEDGEMENTS}

The authors would like to thank SDI Bayswater, Australia for their material support and the staff involved at the Biomaterial Research Laboratory, Faculty of Dentistry, Universiti Malaya, Kuala Lumpur, Malaysia for their assistance.

\section{REFERENCES}

Akova T, Ozkomur A, Uysal H (2006). Effect of food-simulating liquids on the mechanical properties of provisional restorative materials. Dent Mater, 22(12): 1130-1134. https://doi.org/10.1016/j.dental.2005.09 .009
Azlisham NAF, Mahmood Z, Mohamad D (2017). Evaluation of surface roughness and compressive strength of modified glass ionomer cement with coumarin derivatives. f Mech Eng, SI 4(2): 213-220.

Bagheri R, Burrow MF, Tyas MJ (2007). Surface characteristics of aesthetic restorative materials: An SEM study. F Oral Rehabil, 34(1): 68-76. https://doi.org/10.1111/j .1365-2842.2006.01608.x

Berg JH, Croll TP (2015). Glass ionomer restorative cement systems: An update. Pediatr Dent, 37(2): 116-124.

Bollen CM, Lambrechts P, Quirynen M (1997). Comparison of surface roughness of oral hard materials to the threshold surface roughness for bacterial plaque retention: A review of the literature. Dent Mater, 13(4): 258-269. https://doi.org/10.1016/s01095641(97)80038-3

Braem M, Lambrechts P, Vanherle G (1994). Clinical relevance of laboratory fatigue studies. $\mathcal{f}$ Dent, 22(2): 97-102. https://doi.org/10.1016/0300-5712(94) 90010-8

Diem VT, Tyas MJ, Ngo HC, Phuong LH, Khanh ND (2014). The effect of a nanofilled resin coating on the 3-year clinical performance of a conventional highviscosity glass-ionomer cement. Clin Oral Investig, 18(3): 753-759. https://doi.org/10 $.1007 / \mathrm{s} 00784-013-1026-\mathrm{z}$

EMCO-TEST Prüfmaschinen GmbH (2019). Theory of Hardness Testing. Retrieved 18 November 2019, from https://www. emcotest.com/en/the-world-of-hardness -testing/hardness-know-how/theory-of -hardness-testing/knoop-51/advantages - and-disadvantages-of-the-knoop -method-245/ 
Faraji F, Heshmat H, Banava S (2017). Effect of protective coating on microhardness of a new glass ionomer cement: Nanofilled coating versus unfilled resin. $\mathcal{f}$ Conserv Dent, 20(4): 260-263. https://doi.org/10 .4103/JCD.JCD_83_16

Food and Drug Administration (1976). FDA Guidelines for Chemistry and Technology Requirements of Indirect Additive Petitions. Washington, D.C.: Food and Drug Administration.

Frencken JE, Van't Hof MA, Van Amerongen WE, Holmgren CJ (2004). Effectiveness of single-surface ART restorations in the permanent dentition: A meta-analysis. f Dent Res, 83(2): 120-123. https://doi.org/ 10.1177/154405910408300207

Friedl K, Hiller KA, Friedl KH (2011). Clinical performance of a new glass ionomer based restoration system: A retrospective cohort study. Dent Mater, 27(10): 1031-1037. https://doi.org/10.1016/j.dental.2011.07.004

Fukazawa M, Matsuya S, Yamane M (1987). Mechanism for erosion of glass-ionomer cements in an acidic buffer solution. f Dent Res, 66(12): 1770-1774. https://doi .org/10.1177/00220345870660121401

Gemalmaz D, Yoruc B, Ozcan M, Alkumru HN (1998). Effect of early water contact on solubility of glass ionomer luting cements. F Prosth Dent, 80(4): 474-478. https://doi.org/10.1016/s0022-3913(98) 70014-9

Gladys S, Van Meerbeek B, Braem M, Lambrechts P, Vanherle G (1997). Comparative physico-mechanical characterization of new hybrid restorative materials with conventional glass-ionomer and resin composite restorative materials. f Dent Res, 76(4): 883-894. https://doi .org/10.1177/00220345970760041001
Hesse D, Bonifácio CC, Guglielmi Cde A, Bönecker $M$, van Amerongen WE, Raggio DP (2016). Bilayer technique and nano-filled coating increase success of approximal ART restorations: A randomized clinical trial. Int $\mathcal{f}$ Paediatr Dent, 26(3): 231-239. https://doi.org/10 $.1111 /$ ipd.12194

Hesse D, Bonifácio CC, Kleverlaan CJ, Raggio DP (2018). Clinical wear of approximal glass ionomer restorations protected with a nanofilled self-adhesive light-cured protective coating. F Appl Oral Sci, 26: e20180094. https://doi.org/10.1590/1678 -7757-2018-0094

Kao EC (1989). Influence of food-simulating solvents on resin composites and glassionomer restorative cement. Dent Mat, 5(3): 201-208. https://doi.org/10.1016/ 0109-5641(89)90014-6

Lohbauer U, Krämer N, Siedschlag G, Schubert EW, Lauerer B, Mueller FA et al. (2011). Strength and wear resistance of a dental glass-ionomer cement with a novel nanofilled resin coating. Am f Dent, 24(2): 124-128.

Lyapina MG, Tzekova M, Dencheva M, Krasteva A, Yaneva-Deliverska M, Kisselova A (2016). Nano-glass-ionomer cements in modern restorative dentistry. $\mathcal{F} I M A B$ Ann Proc, 22(2): 1160-1165. https://doi.org/10 $.5272 / \mathrm{jimab} .2016222 .1160$

McLean JW (1990). The failed restoration: Causes of failure and how to prevent them. Int Dent f, 40(6): 354-358.

Moshaverinia A, Ansari S, Movasaghi Z, Billington RW, Darr JA, Rehman IU (2008). Modification of conventional glassionomer cements with $\mathrm{N}$-vinylpyrrolidone containing polyacids, nano-hydroxy and fluoroapatite to improve mechanical properties. Dent Mater, 24(10): 13811390. https://doi.org/10.1016/j.dental.2008 .03 .008 
Pacifici E, Bossù M, Giovannetti A, La Torre G, Guerra F, Polimeni A (2013). Surface roughness of glass ionomer cements indicated for uncooperative patients according to surface protection treatment. Ann Stomatol (Roma), 4(3-4): 250-258.

Perrin C, Persin M, Sarrazin J (1994). A comparison of fluoride release from four glass-ionomer cements. Quintessence Int, 25(9): 603-608.

Rogalewicz R, Batko K, Voelkel A (2006). Identification of organic extractables from commercial resin-modified glass-ionomers using HPLC-MS. F Environ Monit, 8(7): 750-758. https://doi.org/10.1039/b604149c

Sideridou ID, Karabela MM (2011). Sorption of water, ethanol or ethanol/water solutions by light-cured dental dimethacrylate resins. Dent Mater, 27(10): 1003-1010. https://doi.org/10.1016/j.dental.2011.06 .007

Sidhu SK, Nicholson JW (2016). A review of glass-ionomer cements for clinical dentistry. F Funct Biomater, 7(3): 16. https://doi.org/10.3390/jfb7030016

Türkün LS, Kanik O (2016). A prospective sixyear clinical study evaluating reinforced glass ionomer cements with resin coating on posterior teeth: Quo vadis? Oper Dent, 41(6): 587-598. https://doi.org/10.2341/15 $-331-\mathrm{C}$
Wilson AD, Kent BE (1971). The glass-ionomer cement, a new translucent dental filling material. If Appl Chem Biotech, 21(11): 313-313. https://doi.org/10.1002/jctb .5020211101

Yap AU, Wee KE (2002). Effects of cyclic temperature changes on water sorption and solubility of composite restoratives. Oper Dent, 27(2): 147-153.

Yap AU, Lee MK, Chung SM, Tsai KT, Lim CT (2003). Effect of food-simulating liquids on the shear punch strength of composite and polyacid-modified composite restoratives. Oper Dent, 28(5): 529-534.

Yildiz E, Simsek M, Pamir Z (2016). Fracture strength of restorations in proximal cavities of primary molars. Scanning, 38(1): 43-49. https://doi.org/10.1002/sca.21239

Yilmaz Y, Eyuboglu O, Kocogullari ME, Belduz N (2006). A one-year clinical evaluation of a high-viscosity glass ionomer cement in primary molars. $\mathcal{F}$ Contemp Dent Pract, 7(1): 71-78. 